\title{
DESENVOLVIMENTO E VALIDAÇÃo DE MÉTODO DE ANÁLISE DE GLIFOSATO EM GRÃOS DE SOJA
}

\author{
Adley Bergson Gonçalves de Abreu
}

Departamento de Química, Universidade Federal de Mato Grosso, 78060-900 Cuiabá - MT, Brasil

Marcia Helena de Rizzo da Matta* e Émerson Montagner

Departamento de Química, Centro de Ciências Exatas e Tecnologia, Universidade Federal de Mato Grosso do Sul, CP 549, 79070-900 Campo Grande - MS, Brasil

Recebido em 6/6/06; aceito em 14/6/07; publicado na web em 3/12/07

\begin{abstract}
DEVELOPMENT AND VALIDATION OF A METHOD OF ANALYSIS OF GLYPHOSATE IN SOY GRAINS. The main objective of this work is to develop an efficient procedure to determine glyphosate in soybean grains. The cleanup of the aqueous extracts was done in two steps, beginning with liquid-liquid partitioning and then solid-phase extraction with anion exchange resin. After derivatization with a mixture of trifluoroacetic anhydride (TFAA) and trifluoroethanol (TFE), quantification was done by gas chromatography coupled to mass spectrometry. The mean recovery and RSD of the spiked samples were, respectively, $80.5 \%$ and $3.1 \%$ at level $0.200 \mathrm{mg} \mathrm{kg}^{-1}$, $93.3 \%$ and $18.7 \%$ at level $0.500 \mathrm{mg} \mathrm{kg}^{-1}$ and $92 \%$ and $3.5 \%$ at level $1.000 \mathrm{mg} \mathrm{kg}^{-1}$. The method was linear in the working range (correlation coefficient $=0.9965$ )
\end{abstract}

Keywords: glyphosate; glyphosate-resistant soybean; pesticide.

\section{INTRODUÇÃO}

A soja Roundup Ready (RR) da Monsanto foi a primeira planta transgênica a ser aprovada para alimentação humana e animal e para cultivo no Brasil. A soja RR foi modificada por técnicas de ADN recombinante (ADNr) pela inserção de um gene da bactéria Agrobacterium sp., que a torna resistente ao herbicida glifosato $(\mathrm{GLI})^{1}$.

O GLI costuma ser pulverizado, sendo em geral absorvido na planta através de suas folhas e dos caulículos novos². Ele inibe a ação da enzima 5-enolpiruvilchiquimato-3-fosfato sintase (EPSPS), afetando a rota de síntese dos aminoácidos aromáticos essenciais, fenilalanina, tirosina e triptofano, os quais são precursores de outros produtos, como lignina, alcalóides, flavonóides e ácidos benzóicos. Os sintomas de sua ação sobre as plantas incluem amarelamento dos meristemas, necrose e morte em dias ou semanas ${ }^{3}$.

No controle químico de ervas daninhas, destacamos a aplicação em pré-emergência e a aplicação em pós-emergência. No primeiro caso, a aplicação é feita imediatamente após o plantio e antes da emergência das plantas daninhas, devendo ser realizada com solo úmido. No segundo caso, a aplicação é feita após a germinação da cultura e das plantas daninhas, sendo que o controle será mais eficiente quanto mais jovens forem as invasoras.

No caso da soja comum, o GLI é aplicado como dessecante e também na pós-emergência das plantas infestantes; na soja modificada geneticamente é aplicado na pré e pós-emergência das plantas infestantes. O limite máximo de resíduo (LMR) para este herbicida, utilizado tanto como dessecante quanto em pós-emergência das plantas infestantes na cultura de soja, foi estabelecido em $10 \mathrm{mg} \mathrm{kg}^{-1}$, com intervalo de segurança de 7 dias quando aplicado como dessecante e não determinado quando o agrotóxico for aplicado em pósemergência das plantas infestantes e pré-emergência da cultura. $\mathrm{O}$ intervalo de segurança é de 56 dias para a modalidade de aplicação em pós-emergência das plantas infestantes na cultura da soja geneticamente modificada ${ }^{5}$.

*e-mail: marciaufms@gmail.com
Como o GLI não é assimilado metabolicamente pela soja transgênica, o mesmo pode vir a se acumular no vegetal e em seus grãos, como é relatado em alguns estudos ${ }^{6,7}$, e, sendo a soja muito utilizada na alimentação humana ou de outros animais, torna-se imprescindível o desenvolvimento de estudos e monitoramento deste herbicida em seus grãos. No Brasil, o GLI é utilizado principalmente nas culturas de arroz, café, cacau, milho, cana-de-açúcar, soja, frutas cítricas, seringueira e banana, sendo também usado no controle de plantas aquáticas ${ }^{8}$.

O GLI, [N-(fosfonometil)-glicina], é formado por uma glicina e um radical aminofosfato, substituinte de um dos hidrogênios do grupo $\alpha$-amino. É classificado como herbicida não seletivo, sistêmico e pós-emergente. O seu grande sucesso deve-se à sua elevada eficiência na eliminação de ervas daninhas com a vantagem de ter uma baixa toxicidade aos que o manipulam ${ }^{9}$.

O GLI apresenta uma baixa toxicidade aguda, o seu $\mathrm{DL}_{50}$ oral varia entre 1950 a $5000 \mathrm{mg} \mathrm{kg}^{-1}$ de massa corpórea em camundongos, ratos e cabras ${ }^{10}$. Apesar do glifosato ser citado como pouco tóxico, há evidências de efeitos deletérios no ambiente, principalmente devido à resistência adquirida por algumas espécies de ervas, após o uso prolongado do herbicida ${ }^{2}$. Um estudo com ratas no período de gestação, para as quais se administrou doses de GLI Roundup ${ }^{\circledR}$ diluído em água, constatou que este herbicida provocou retardamento no desenvolvimento do esqueleto dos fetos ${ }^{11}$. Em um outro estudo, observou-se que ele pode alterar a atividade enzimática de prenhes e de seus fetos ${ }^{12}$.

Novos estudos estão surgindo para averiguar o potencial de contaminação deste herbicida em cereais geneticamente modificados resistentes ao mesmo. Granby e colaboradores ${ }^{13}$ analisaram GLI em cereais através de um método simples e rápido utilizando cromatografia em fase líquida de alta eficiência (CLAE), sendo a extração efetuada com água por ultrassonificação, a purificação e separação feitas com uma coluna em fase reversa à base de poliestireno ligada em série com uma coluna cromatográfica, sendo a detecção efetuada por espectrometria massa/massa com ionização por eletrospray. Há estudos de análise de GLI em cereais que empregam o adsorvente C-18 em extração em fase sólida (EFS), substituindo as resinas trocadoras de íons, comumente utilizadas nas etapas de purificação dos extratos ${ }^{14}$. 
Existem poucos artigos na literatura que abordam diretamente a análise de GLI em soja transgênica. Dentre os encontrados, temse o trabalho feito por Arregui e colaboradores ${ }^{7}$, que analisaram o GLI e seu principal metabólito, o ácido aminometilfosfônico (AMPA) em plantas e grãos de soja. O grupo monitorou 5 regiões da Argentina entre os anos de 1997 a 1999, encontrando quantidades de GLI entre 1,9 a 4,4 $\mathrm{mg} \mathrm{kg}^{-1}$ nas plantas e 0,1 a $1,8 \mathrm{mg} \mathrm{kg}^{-1}$ em grãos. Traços do AMPA também foram encontrados, demonstrando que ocorreu metabolização do GLI.

Os efeitos da degradação do GLI em AMPA pelo metabolismo das plantas de soja resistentes ao mesmo também foram estudados, e observou-se que a formação do AMPA pode decorrer em prejuízos nas culturas de soja geneticamente modificadas resistentes ao GLI, visto que o seu metabólito também apresenta caráter fitotóxico ${ }^{6}$.

O presente trabalho apresenta um método validado de análise de GLI em grãos de soja, com duas etapas de purificação dos extratos. A primeira por partição com clorofórmio e a segunda por extração em fase sólida com resina trocadora de ânions, sendo que a escolha de uma resina aniônica deveu-se ao fato de que, nas formulações comerciais, o GLI está na forma de um sal ácido e, sendo a extração realizada em meio aquoso, ele estará na sua forma aniônica. A derivação, necessária para a análise efetuada por cromatografia em fase gasosa acoplada à espectrometria de massa, foi feita com a adição de anidrido trifluoroacético (TFAA) e trifluoroetanol (TFE), sob aquecimento a $100{ }^{\circ} \mathrm{C}$ por $1 \mathrm{~h}$. A análise cromatográfica foi efetuada $24 \mathrm{~h}$ após a derivação, devido à instabilidade do derivado ${ }^{15}$.

Para a validação, foram observados os seguintes critérios: seletividade, intervalo de trabalho, linearidade, sensibilidade, exatidão, precisão, limite de detecção (LD), limite de quantificação (LQ).

\section{PARTE EXPERIMENTAL}

\section{Padrões, soluções e materiais}

Utilizou-se padrão de GLI (98\%) certificado (Dr. Ehrenstorfer $\mathrm{GmbH}$, Augsburg -Alemanha). Preparou-se solução estoque na concentração de $109 \mathrm{mg} \mathrm{L}^{-1}$ e solução de trabalho de $10 \mathrm{mg} \mathrm{L}^{-1}$, utilizando-se água ultrapurificada (Milli $\left.\mathrm{Q}{ }^{\circledR}\right)$.

Preparou-se solução água:metanol: $\mathrm{HCl}$, na proporção de 140:60:2,7 (v/v/v), respectivamente, com metanol (grau HPLC, $100,0 \%$ Mallinckrodt) e $\mathrm{HCl}$ concentrado (36,9\%, Mallinckrodt); soluções de $\mathrm{HCl}$ 6,0 mol L-1 e NaOH (98\%, Dinâmica) 1,0 mol L-1 foram preparadas com água ultrapurificada.

Utilizou-se papel de $\mathrm{pH}$ Universalindikator ( $\mathrm{pH} 0-14$, Merck). Foram utilizadas resinas trocadoras de íons, Amberlite IRA-420 $\left(\mathrm{Cl}^{-}\right)$e Amberlite IR-120 $\left(\mathrm{Na}^{+}\right)$, ambas da Synth; colunas de EFS (5 $\mathrm{mL}, 500 \mathrm{mg}$ ) C-18 e CN (Supelco) e colunas de vidro preparadas com 4 g de adsorvente Florisil (Merck); TFAA (99,5\%, Vetec) e TFE (99\%, J. T. Baker); acetato de etila (grau HPLC, J. T. Baker) e clorofórmio (grau HPLC, Synth).

\section{Preparo das amostras}

Para a validação do método, usaram-se grãos de soja orgânica (cultivar BR 36) não transgênica. Os grãos de soja foram triturados em um liquidificador industrial (VISA) e, posteriormente, peneirados em malha de 35 mesh.

\section{Fortificação das amostras}

Amostras de 1,00 g da farinha de soja foram colocadas separadamente em frascos de vidro $(50 \mathrm{~mL})$. Procedeu-se à fortificação com a adição de GLI nas concentrações de 200, 500 e $1000 \mu \mathrm{g} \mathrm{kg}^{-1}$; agitan- do-se energicamente por 1 min e deixando-se em repouso por $2 \mathrm{~h}$ à temperatura ambiente para secura completa da solução contaminante. Todos os níveis de fortificação foram efetuados em triplicatas.

\section{Escolha do material adsorvente}

Realizaram-se testes com diferentes adsorventes com o intuito de averiguar suas eficiências na eliminação das impurezas contidas na amostra. Foram utilizados adsorventes de EFS apolar, de média polaridade e polar, C-18, CN e florisil, respectivamente. O condicionamento, bem como a eluição, foi efetuado com 10,0 mL de metanol e 10,0 mL de água ultrapurificada subseqüentemente.

As resinas, catiônica (IR-120) e aniônica (IRA-420), foram utilizadas com o objetivo de reter o analito e deixar que as impurezas percolassem pela coluna. A resina catiônica foi condicionada com 20,0 mL HCL 0,2 mol L-1 e a resina aniônica foi condicionada com $20 \mathrm{~mL}$ de água ultrapurificada.

Os adsorventes C-18, CN e florisil foram testados e mostraramse ineficientes, sendo as amostras tratadas com estes descartadas devido ao alto grau de impurezas contidas nelas, o que inviabilizou a análise cromatográfica. A resina catiônica, a princípio, mostrouse eficiente, mas quando as amostras foram secas em evaporador rotativo, observou-se formação de precipitados de $\mathrm{NaCl}$, o que também inviabilizou a análise cromatográfica. A purificação com a resina aniônica mostrou-se a mais eficaz dentre as estudadas e, portanto, foi escolhida para a etapa de purificação das amostras.

\section{Extração do GLI}

Adicionaram-se 10,0 mL de água ultrapurificada às amostras de farinha de soja fortificadas $(1,00 \mathrm{~g})$, agitou-se manualmente por $1 \mathrm{~min}$; deixou-se a amostra em repouso por uma noite em geladeira. Agitou-se novamente a amostra por $1 \mathrm{~min}$; em seguida todo o seu conteúdo foi transferido para um tubo de ensaio de $15 \mathrm{~mL}$, sendo então centrifugada a $3000 \mathrm{rpm}$ por $5 \mathrm{~min}$ em centrífuga (4K15, Sigma). Retirou-se uma alíquota de $5,0 \mathrm{~mL}$ do sobrenadante para a purificação.

\section{Purificação das amostras}

Adicionou-se uma alíquota 2,0 mL de clorofórmio para retirar compostos solúveis em solvente orgânicos; agitou-se a mistura energicamente por 2 min e centrifugou-se novamente nas mesmas condições da centrifugação anterior. Em seguida, transferiu-se todo o sobrenadante (fase aquosa), para um recipiente de $50 \mathrm{~mL}$; adicionaram-se 5,0 mL de água ultrapurificada e gotas de solução de $\mathrm{NaOH}$ $\left(1,0 \mathrm{~mol} \mathrm{~L}^{-1}\right)$ para ajustar o $\mathrm{pH}$ entre 10 e 11 , sendo este medido com auxílio de papel indicador.

A segunda etapa de purificação foi efetuada utilizando-se resina trocadora de ânions fortemente básica (IRA-420) empacotada em uma coluna de vidro $(15 \mathrm{~cm} ; \varnothing=2,0 \mathrm{~cm})$, composta de torneira para controle da vazão e lã de vidro para reter a resina na coluna. A coluna foi empacotada com 4,0 mL da resina. Em seguida foi condicionada com 50,0 mL de água ultrapurificada, para retirar o excesso de íons cloreto. O extrato alcalinizado foi adicionado à coluna, lavando-se o recipiente que o continha com três parcelas de $5,0 \mathrm{~mL}$ de água ultrapurificada. A passagem do extrato pela coluna ocorreu pela gravidade, à vazão de $3 \mathrm{~mL}$ min $^{-1}$.

$\mathrm{O}$ analito retido na resina, foi eluído com $1 \times 1,0 \mathrm{~mL}$ e $2 \times 2,0$ $\mathrm{mL}$ de $\mathrm{HCl}$ 6,0 $\mathrm{mol} \mathrm{L}^{-1}$ e 5,0 $\mathrm{mL}$ de água ultrapurificada, pela gravi-

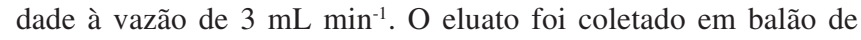
fundo redondo de $50 \mathrm{~mL}$ e levado à secura em evaporador rotativo (TE-120, Tecnal), a uma temperatura de $50{ }^{\circ} \mathrm{C}$ e pressão reduzida 
de $-660 \mathrm{~mm} \mathrm{Hg}$. Dissolveu-se o extrato seco com $3 \times 0,4 \mathrm{~mL}$ de solução água:metanol:HCl (160:40:2,7) (v/v/v), transferindo-o quantitativamente para ampola de vidro fabricada no laboratório.

\section{Derivação da amostra}

As amostras contidas nas ampolas de vidro, do item anterior, foram evaporadas à secura sob fluxo de nitrogênio, e adicionadas $800 \mu \mathrm{L}$ de TFAA e $400 \mu \mathrm{L}$ de TFE. Após lacrarem-se as ampolas com auxílio do bico de Bunsen, foram colocadas em estufa (TE395 , Tecnal) a $100{ }^{\circ} \mathrm{C}$, por $1 \mathrm{~h}$. Após atingir a temperatura ambiente, secou-se novamente sob fluxo de nitrogênio e retomou-se as amostras a 1,0 mL com acetato de etila, sendo mantidas em geladeira por $24 \mathrm{~h}$ para posterior análise cromatográfica.

\section{Análise cromatográfica}

As análises foram efetuadas em um cromatógrafo a gás (GC-17A, Shimadzu), acoplado a um espectrômetro de massas (QP-5000, Shimadzu), equipado com uma coluna capilar HP-5 (5\%-fenilmetilpolissiloxano) da J\&W Scientific, de $30 \mathrm{~m}$ de comprimento, 0,25 $\mathrm{mm}$ de diâmetro interno e $0,25 \mu \mathrm{m}$ de espessura do filme. $\mathrm{O}$ volume de injeção foi de $1,0 \mu \mathrm{L}$, no modo sem divisão da amostra, splitless.

A temperatura inicial da coluna de $70{ }^{\circ} \mathrm{C}$ foi mantida por $2 \mathrm{~min}$, em seguida foi elevada até $200^{\circ} \mathrm{C}\left(30^{\circ} \mathrm{C} \mathrm{min}^{-1}\right)$ e depois à temperatura de $270{ }^{\circ} \mathrm{C}\left(10^{\circ} \mathrm{C}\right.$ min $\left.^{-1}\right)$, sendo esta última mantida por 6,74 min. A temperatura do injetor foi de $260{ }^{\circ} \mathrm{C}$ e a temperatura da interface foi de $270{ }^{\circ} \mathrm{C}$. A pressão na coluna foi de $100 \mathrm{kPa}$, o gás de arraste foi o hélio (5.0 analítico, White Martins), a uma vazão de $1,5 \mathrm{~mL} \mathrm{~min}^{-1}$.

Os espectros foram obtidos pela técnica de impacto eletrônico, com energia de $70 \mathrm{eV}$, com programação para monitoramento de íon selecionado (modo SIM). Para geração dos cromatogramas, do fragmentograma e quantificação foi utilizado o software CLASS5000 da Shimadzu.

\section{RESULTADOS E DISCUSSÃO}

\section{Considerações sobre o procedimento analítico}

O processo de trituração da soja foi efetuado sem que ocorresse a formação de óleo na soja triturada. Foram utilizados pequenos volumes da solução contaminante para que não ocorressem interferências significativas, além das interações que ocorrem na própria amostra, visto que a soja possui enzimas denominadas lipoxigenases que, quando em contato com a água fria, iniciam uma reação que produz compostos como aldeídos, cetonas e álcoois ${ }^{16}$.

A extração do GLI em matrizes de farinha de soja mostrou-se eficiente, evidenciando que a molécula do GLI não foi alterada pelas enzimas contidas na soja em presença de água.

A primeira parte do processo de purificação dos extratos foi constituída de extração por partição entre a amostra aquosa e clorofórmio, o qual pode ser substituído por diclorometano, conforme o trabalho de Alferness e colaboradores ${ }^{17}$. Com auxílio de uma micropipeta observou-se que cerca de 0,3 a $0,4 \mathrm{~mL}$ de substâncias solúveis no solvente orgânico foram retiradas da amostra.

A resina aniônica, ao ser condicionada com água ultrapurificada, tem o excesso de íons cloreto retirado, diminuindo o seu caráter básico. Ao adicionar a amostra, com pH entre 10 e 11, maior que o pH da coluna, onde o GLI apresenta total dissociação, os ânions cloretos da resina são substituídos pelos ânions de GLI. A eluição é efetuada com excesso de íons cloreto, restabelecendo a resina ao seu estado inicial.
Purificações de extratos com o pH menor que 10 e maior que 11 também foram estudadas. Com o pH menor que 10, observouse que a amostra não foi completamente limpa. Com o $\mathrm{pH}$ maior que 11, observou-se que ocorreu a saturação da resina com excesso de íons $\left(\mathrm{OH}^{-}\right)$e proteínas ionizadas com carga negativa, dificultando a percolação da amostra pela coluna.

Após a etapa de derivação ter sido concluído e a amostra seca, observou-se a presença de um precipitado. Este fato ocorreu devido à derivação de proteínas, aminoácidos, ou outras substâncias ionizáveis contidas na soja, ou ambas, que permaneceram na amostra, após as etapas de purificação. Esta derivação provoca o aumento do tamanho de suas estruturas moleculares devido ao acréscimo de substituintes organofluorados, fazendo com que haja formação de um precipitado, após a secura do extrato. O precipitado formado mostrou-se pouco solúvel em acetato de etila. A Figura 1 ilustra a etapa de derivação do GLI.

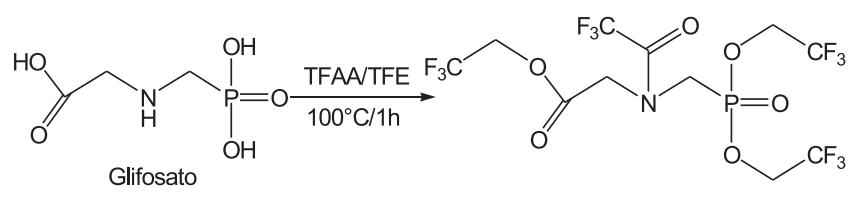

Glifosato-Derivado

Figura 1. Esquema de conversão do GLI em seu respectivo derivado

\section{Considerações sobre a análise cromatográfica}

O tempo de retenção do GLI derivado foi de 5,84 min, sendo que a gaussiana apresentou boa resolução (Figura 2). Os íons escolhidos para o monitoramento foram $511 \mathrm{~m} / \mathrm{z}$ (íon molecular do GLI derivado) e $411 \mathrm{~m} / \mathrm{z}$ decorrente da perda de um dos substituintes $\left(\mathrm{OCH}_{2} \mathrm{CF}_{3}\right)$, visto que estes não sofreram interferências de substâncias presentes na amostra.

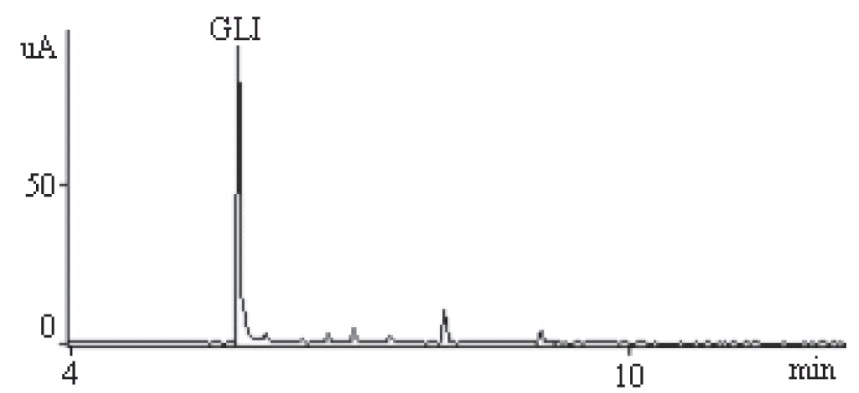

Figura 2. Cromatograma do composto GLI derivado (500 ng)

\section{Validação do método}

\section{Seletividade}

O método proposto apresentou boa seletividade como pode ser observado na Figura 3, onde são comparados cromatogramas de um composto GLI derivado com cromatogramas de amostras testemunha (amostra correspondente à matriz analisada, isenta de contaminação pelo analito em estudo). Na da Figura 3 pode-se observar que não existem picos cromatográficos provenientes da amostra testemunha no tempo de retenção $\left(\mathrm{t}_{\mathrm{r}}\right)$ do GLI (5,84 min), pois o primeiro sinal provindo da amostra testemunha é observado em 6,06 min.

Na Figura 4 são apresentadas as análises da amostra testemunha. O cromatograma A mostra os sinais de substâncias contidas na matriz, que foi submetida aos mesmos processos de extração, purificação e derivação, com análise cromatográfica após 24 h da derivação. O cromatograma $\mathrm{B}$, com análise cromatográfica após $48 \mathrm{~h}$ 

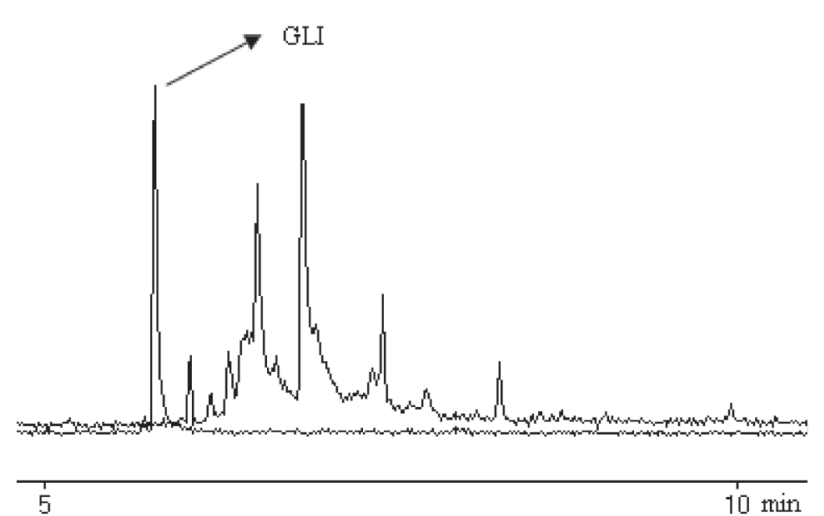

Figura 3. Sobreposição dos cromatogramas da amostra testemunha, linha de base superior, com o da amostra do composto GLI derivado (1000 ng), linha de base inferior

após a derivação, apresentou sinais semelhantes aos do cromatograma $\mathrm{A}$, mas com maior intensidade, o que pode ser devido à degradação dos constituintes da amostra durante o período de $48 \mathrm{~h}$, produzindo compostos que geram os íons monitorados. Apesar de ocorrer um aumento na intensidade nos sinais no cromatograma B, não foi observado neste cromatograma nenhum sinal antes de 6,0 min, o que garante que as análises das amostras fortificadas possam ser efetuadas em até $48 \mathrm{~h}$ após a derivação, com excelente seletividade.
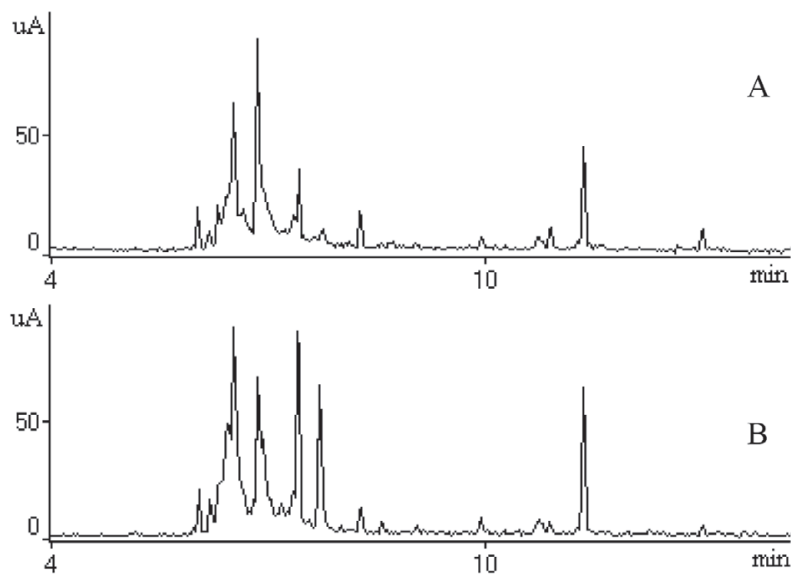

Figura 4. Cromatograma da amostra testemunha, após 24 h da derivação (A). Cromatograma da amostra testemunha, após $48 \mathrm{~h}$ da derivação (B)

\section{Limite de Detecção e Quantificação}

Os limites de detecção (LD) e de quantificação (LQ) do método foram calculados através da relação sinal/ruído de 3 e 10 vezes, respectivamente ${ }^{18}$. Os valores de $\mathrm{LD}$ e LQ, relativos ao método nas condições analíticas utilizadas, foram de 60 e $200 \mu \mathrm{g} \mathrm{kg}^{-1}$, respectivamente. O limite de quantificação $\left(200 \mu \mathrm{g} \mathrm{kg}^{-1}\right)$ para o método proposto foi satisfatório, pois é inferior ao limite de quantificação encontrado no trabalho de Hogendoorn ${ }^{14}$, que foi de $500 \mu \mathrm{g} \mathrm{kg}^{-1}$ para análise de GLI em cereais; também é inferior ao limite máximo de resíduos (LMR) estabelecido pela ANVISA $^{5}$ para a soja (10,0 $\mathrm{mg} \mathrm{kg}^{-1}$ ) o que possibilita a aplicação deste método na averiguação do nível de contaminação deste cereal.

\section{Linearidade}

Para a obtenção da curva analítica, foi determinada primeiramente a faixa de trabalho. A faixa escolhida foi de 200 a $1000 \mu \mathrm{g}$ $\mathrm{kg}^{-1}$. O coeficiente de correlação (r) foi de 0,9965 , mostrando que existe uma forte correlação entre as concentrações estudadas e o sinal gerado pelo equipamento. A curva analítica obtida pode ser expressa pela equação: $\mathrm{y}=3,819 \mathrm{x}-185,2$.

\section{Ensaios de recuperação}

Os ensaios de recuperação foram utilizados para averiguação da precisão e exatidão do método. O ensaio de recuperação constitui o método mais utilizado para validação de processos analíticos.

A recuperação está relacionada com a exatidão, pois reflete a quantidade de determinado analito, recuperado no processo, em relação à quantidade real presente na amostra. A exatidão é expressa como erro sistemático percentual, inerente ao processo. O erro sistemático ocorre pela perda da substância devido à baixa recuperação da extração, medidas volumétricas imprecisas ou substâncias interferentes na $\operatorname{amostra}^{19}$

Segundo o INMETRO ${ }^{20}$, a recuperação é calculada da seguinte forma:

Recuperação $(\%)=\left(\frac{\mathrm{C}_{1}-\mathrm{C}_{2}}{\mathrm{C}_{3}}\right) \times 100$

onde: $\mathrm{C}_{1}=$ concentração determinada na amostra fortificada; $\mathrm{C}_{2}=$ concentração determinada na amostra não fortificada; $\mathrm{C}_{3}=$ concentração adicionada.

A exatidão foi avaliada usando um mínimo de 9 determinações, sendo estas com 3 níveis de concentrações, com 3 réplicas em cada nível ${ }^{21}$. Os resultados obtidos através dos ensaios de recuperação encontram-se na Tabela 1 .

Tabela 1. Resultados dos ensaios de recuperação

\begin{tabular}{lcccc}
\hline $\begin{array}{l}\text { GLI } \\
\text { adicionado (ng) }\end{array}$ & $\begin{array}{c}\text { Recuperação } \\
(\text { ng) })^{a}\end{array}$ & $\begin{array}{c}\text { Recuperação } \\
(\%)^{\mathrm{a}}\end{array}$ & D.P. $^{\mathrm{b}}$ & $\begin{array}{c}\mathrm{CV}^{\mathrm{c}} \\
(\%)\end{array}$ \\
\hline 200 & 166 & 83,0 & 2,5 & 3,1 \\
& 161 & 80,5 & & \\
500 & 156 & 78,0 & & \\
& 562 & 112,4 & 17,4 & 18,7 \\
& 447 & 89,4 & & \\
1000 & 391 & 78,2 & & \\
& 913 & 91,3 & 3,2 & 3,5 \\
& 955 & 95,5 & & \\
\hline
\end{tabular}

${ }^{a}$ GLI recuperado para cada nível de fortificação; bdesvio padrão para cada nível de fortificação; ' ${ }^{c}$ coeficiente de variação percentual para cada nível de fortificação.

Os resultados obtidos foram considerados excelentes, pois as recuperações estão compreendidas na faixa entre 70 e 120\%, a qual é recomendada pela literatura para análise de resíduos de pesticidas ${ }^{19,21}$, o que indica que o método é exato. Observa-se que as menores recuperações foram obtidas no nível correspondente ao LQ do método. No nível de fortificação de 500 ng ocorreram variações na recuperação, o que elevou o desvio padrão e o coeficiente de variação percentual CV (\%), mas este não ultrapassou o limite estabelecido de $20 \%$, valor aceitável para análise de resíduos de pesticidas ${ }^{21-23}$, mostrando desta forma que o método é bastante preciso.

\section{Tratamento estatístico do teste de recuperação}

Para avaliar a exatidão podem-se calcular as médias dos três níveis de fortificação aplicando-se o teste de significância, utilizando o 
Teste $\mathrm{t}$ de Student ${ }^{19}$. Os valores utilizados estão contidos na Tabela 2.

Os valores foram submetidos ao teste hipótese, sendo estabelecida como hipótese nula $\left(\mathrm{H}_{0}\right): \mu=100 \%$ e como hipótese alternativa $\left(\mathrm{H}_{1}\right): \mu \neq 100 \%$. O valor de $t$ experimental foi calculado através da Equação ${ }^{24}$ :

$t_{\exp }=\frac{\left(\overline{\mathrm{X}}_{\operatorname{Re} c}-\mu\right) \sqrt{n}}{S_{\operatorname{Re} c}}$

onde: $\mathrm{X}_{\mathrm{Rec}}$ é a média de recuperação do método, $\mu$ é o valor esperado (100\%), n o tamanho da amostra (3) e $\mathrm{S}_{\mathrm{Rec}}$ o desvio padrão das médias de recuperação de cada nível de fortificação.

Tabela 2. Médias das recuperações para cada nível de fortificação, média de recuperação do método, desvio padrão e valor de $t$ calculado.

\begin{tabular}{lcccc}
\hline $\begin{array}{l}\text { Nível } \\
\text { Fortificação }\end{array}$ & $\begin{array}{c}\text { Recuperação } \\
(\%)\end{array}$ & $\begin{array}{l}\mathrm{X}_{\mathrm{Rec}}{ }^{\mathrm{b}} \\
(\%)\end{array}$ & $\left.\left.\mathrm{S}_{\text {rec }}{ }^{\mathrm{c}}\right|^{\mathrm{a}}\right)$ & $\left.t_{\text {exp }}\right|^{\mathrm{d}}$ \\
\hline 200 & 80,5 & & & \\
500 & 93,3 & 88,6 & 7,04 & 2,8 \\
1000 & 92,0 & & & \\
\hline
\end{tabular}

${ }^{a}$ Médias das recuperações para cada nível de fortificação; ${ }^{b}$ média de recuperação do método; ${ }^{\mathrm{c}}$ desvio padrão da média das recuperações de cada nível de fortificação; ${ }^{\mathrm{d}} t$ de Student calculado.

O valor calculado de $t_{\text {exp }}$ foi de 2,8 e o valor de $t$ tabelado $\left(t_{\text {tab }}\right) 4,3$ com $95 \%$ de confiança e $n-1$ graus de liberdade. Como $\left|t_{\text {exp }}\right| \leq t_{t a b}$, aceita-se a hipótese nula $\left(\mathrm{H}_{0}\right)$, ou seja, não se pode afirmar que existam diferenças significativas entre o valor esperado e o encontrado, com $95 \%$ de confiança entre as recuperações obtidas e o valor esperado, mostrando que o método proposto é suficientemente exato.

\section{CONCLUSÃO}

O método proposto foi considerado exato devido às excelentes recuperações, estando dentro da faixa aceita para análise de resíduos de pesticidas (70-120\%), e por não mostrar diferenças significativas entre a média das recuperações com o valor desejado, como determinado no cálculo estatístico empregando-se o teste $t$ de Student. Este também foi considerado preciso devido aos valores CV (\%), estando todos abaixo do limite estipulado para análise de resíduos de pesticidas (20\%). O método utilizado, com duas etapas de purificação, uma por partição com solvente orgânico e outra por extração em fase sólida com resina aniônica, e análise por cromatografia em fase gasosa acoplada à espectrometria de massas, pode ser utilizado na análise de matrizes reais com alto grau de confiabilidade e, desta forma, contribuir para o monitoramento de pesticidas, neste caso o GLI, em culturas geneticamente modificadas ou não, visto que este herbicida também é aplicado em culturas de soja comum como dessecante.

\section{MATERIAL SUPLEMENTAR}

No material suplementar, disponível gratuitamente em http:// quimicanova.sbq.org.br na forma de arquivo PDF, estão contidos o fragmentograma do GLI (Figura 1S) e exemplos de cromatogramas de amostras fortificadas nos níveis 200 e $1000 \mu \mathrm{g} \mathrm{kg}^{-1}$ (Figura 2S).

\section{AGRADECIMENTOS}

Ao CNPq, à FUNDECT e à UFMS.

\section{REFERÊNCIAS}

1. Kleba, J. B.; Cadernos de Ciência \& Tecnologia: CC\&T 1998, 15, 9.

2. de Amarante Jr., O. P.; dos Santos, T. C. R.; Brito, N. M.; Ribeiro, M. L.; Quim. Nova 2002, 25, 589.

3. Börjesson, E.; Torstensson, L.; J. Chromatogr., A 2000, 886, 207.

4. http://sistemasdeproducao.cnptia.embrapa.br/FontesHTML/Feijao/ CultivodoFeijaoComumRO/daninhas.htm, acessada em Janeiro 2007.

5. http://www.anvisa.gov.br/toxicologia/monografias/g01.pdf, acessada em Maio 2006.

6. Reddy, K. N.; Rimando, A. M.; Duke, S. O.; J. Agric. Food Chem. 2004, 52, 5139.

7. Arregui, M. C.; Lenardón, A.; Sanchez, D.; Maitre, M. I.; Scotta, R.; Enrique, S.; Pest Manage. Sci. 2003, 60, 163.

8. Andrei, E.; Compêndio de defensivos agrícolas: guia prático de produtos fitossanitários para uso agrícola, $4^{\mathrm{a}}$ ed., Andrei Editora Ltda: São Paulo, 1993.

9. de Amarante Jr., O. P.; dos Santos, T. C. R.; Brito, N. M.; Ribeiro, M. L.; Quim. Nova 2002, 25, 420.

10. http://www.who.int/water_sanitation_health/dwq/chemicals/glyphosateampa290605.pdf, acessada em Maio 2006.

11. Dallegrave, E.; Mantese, F. G.; Coelho, R. S.; Pereira, J. D.; Dalsenter, P. R.; Langeloh, A.; Toxicol. Lett. 2003, 142, 45.

12. Daruich, J.; Zirulnik, F.; Gimenez, M. S.; Environ. Res. 2001, 85, 226.

13. Granby, K.; Johannesen, S.; Vahl, M.; Food Addit. Contam. 2003, $20,692$.

14. Hogendoorn, E. A.; Ossendrijver, F. M.; Dijkman, E.; Baumann, R.; J. Chromatogr., A 1999, 833, 67.

15. de Souza, T. A.; da Matta, M. H. de R.; Montagner, E.; de Abreu, A. B. G.; Quim. Nova, 2006, 29, 1372.

16. http://www.cnpso.embrapa.br/soja_alimentacao/index.php?pagina=3 acessada em Maio 2006.

17. Alferness, P. L.; Wiebe, L. A.; Anderson, L.; Bennett, O.; Bosch, M.; Clark, D.; Claussen, F.; Colin, T.; Cook, C.; Davis, H.; Ely, V.; Graham, D.; Grazzini, R.; Hickes, H.; Holland, P.; Hom, W.; Ingram, R.; Ling, Y.; Markley, B.; Peoples, G.; Pitz, G.; Robert, G.; Robinson, C.; Sen, L.; Sensue, A.; South, N.; Steginsky, C.; Summer, S.; Trower, T.; Wieczorek, P.; Zheng, S.; J. AOAC Int. 2001, 84, 823.

18. Leite, F.; Validação em Análise Química, $4^{\mathrm{a}}$ ed., Ed. Átomo: Campinas, 2002

19. Brito, N. M.; Ribeiro, M. L.; Amarante Junior, O. P.; Polese, L.; Pesticidas: R. Ecotox. e Meio Ambiente 2003, 13, 129.

20. http://www.inmetro.gov.br/kits/doqcgcre008r01.pdf, acessada em Maio 2006.

21. http://www.ich.org/LOB/media/MEDIA417.pdf, acessada em Maio 2006.

22. Parker, G. A.; J. AOAC Int. 1991 74, 868

23. Thier, H. P.; Zeumer, H.; Manual of pesticides analysis, Verlag Chemie: New York, 1987.

24. Miller, J. N.; Miller, J. C.; Estadística y Quimiometría para Química Analítica, $4^{\text {a }}$ ed., Ed. Pearson Educación S.A: Madrid, 2002. 


\section{DESENVOLVIMENTO E VALIDAÇÃO DE MÉTODO DE ANÁLISE DE GLIFOSATO EM GRÃOS DE SOJA}

Adley Bergson Gonçalves de Abreu

Departamento de Química, Universidade Federal de Mato Grosso, 78060-900 Cuiabá - MT, Brasil

Marcia Helena de Rizzo da Matta* e Émerson Montagner

Departamento de Química, Centro de Ciências Exatas e Tecnologia, Universidade Federal de Mato Grosso do Sul, CP 549, 79070-900 Campo Grande - MS, Brasil

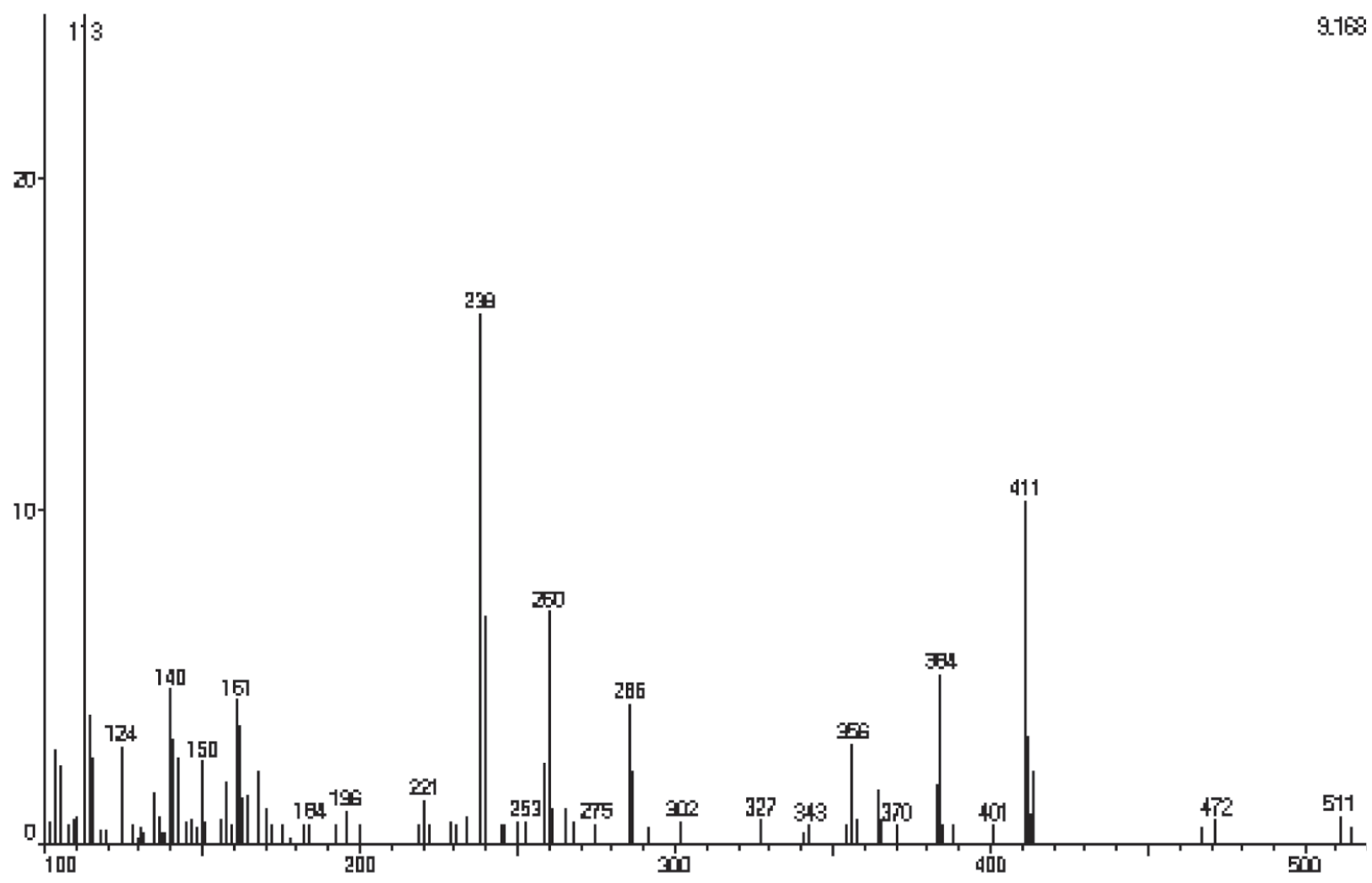

Figura 1S. Fragmentograma do composto GLI derivado
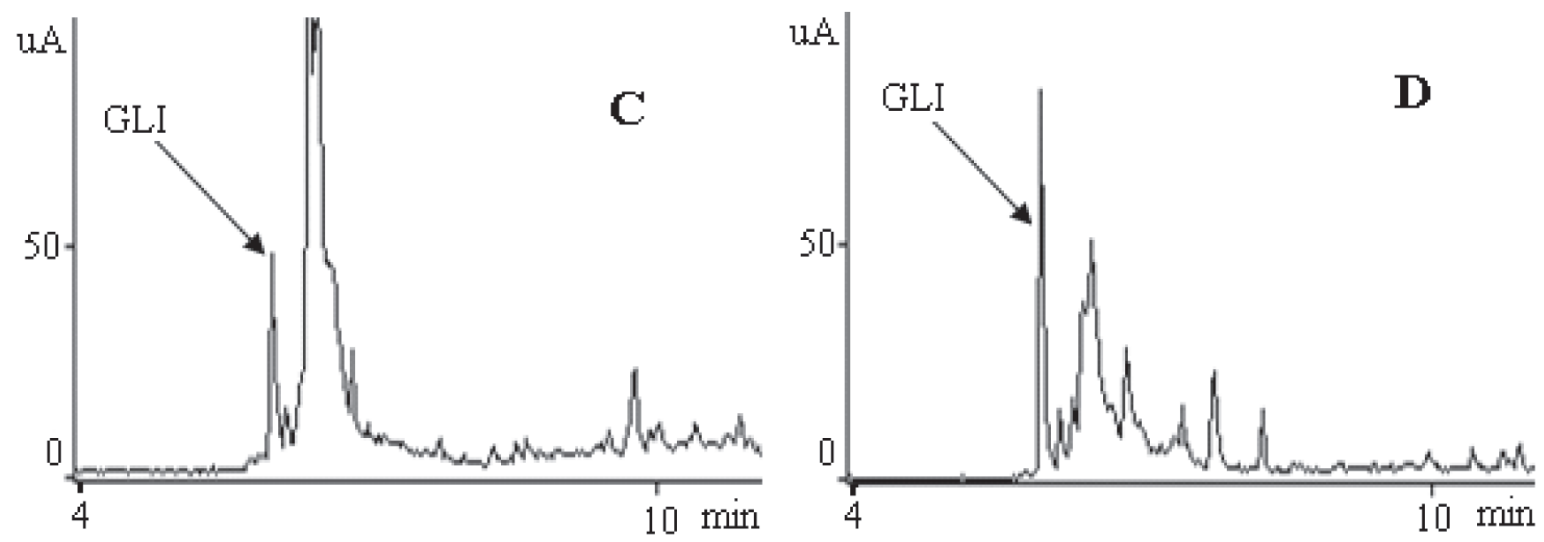

Figura 2S. Cromatograma de dois níveis de fortificação. C (200 $\left.\mu \mathrm{g} \mathrm{kg}^{-1}\right) ; D\left(1000 \mu \mathrm{g} \mathrm{kg}^{-1}\right)$

*e-mail: marciaufms@gmail.com 